\title{
A Numerical Simulation Approach for Sunspot Area Calculation
}

\author{
Souad Saadi \\ Energy Physics Laboratory \\ Department of Physics \\ University of Constantine 1 \\ Constantine, Algeria \\ saadi.acwa@yahoo.fr
}

\author{
Abla Chaker \\ Energy Physics Laboratory \\ Department of Physics \\ University of Constantine 1 \\ Constantine, Algeria \\ Chakamine@yahoo.fr
}

\begin{abstract}
The aim of this paper is the numerical simulation of the sunspot area (SSA) and its location on the walls and on the floor of a room with a single window facing south. The input parameters of the calculation code are the geometry of the cell located in the site of Ksar Challala $(35.1 \mathrm{~N}, 2.19 \mathrm{E}, 800 \mathrm{~m})$ in Algeria for the 21st of March, June and December. The SSA is a function of the window's area, the date and time, the orientation of the room, the altitude and the azimuth of the sun. The obtained results show that the western wall is affected by the sun in the morning, the eastern wall in the afternoon, the floor and the north wall in the middle of the day. By increasing the window area from $1 \mathrm{~m}^{2}$ to $2 \mathrm{~m}^{2}$ we found that the SSA increases considerably.
\end{abstract}

Keywords-window; sunspot; residence; time-direct gains

\section{INTRODUCTION}

A window is an essential element of the passive approach of bioclimatic design as it has a significant influence on the energy efficiency of buildings [1]. From a thermal point of view, it is one of the most sensitive elements standing between the indoor and the outdoor environment. It may be integrated in the building envelope but, unlike the other parts of the envelope, it allows the light to pass and often offers a lower resistance to heat transmission. On the other hand, it can capture solar energy to heat the indoor environment when the solar energy is high and the outside temperature is low [2-4]. Authors in [4-5] showed, by the use of DEROB-LTH software in order to simulate the thermal behaviour of passive houses, that using high-performance windows would be better than having windowless insulated walls. The dimensions of the most appropriate windows depend on the orientation of the building and its thermal mass. French thermal regulation proposes a reference value of $16.5 \%$ (percentage of glazed area in relation to living space), but this value can be as high as $22 \%$. Higher values would increase the risks of overheating during the summer period [4]. The need to use precise simulation models for the distribution of solar energy in buildings has become an essential subject of research in recent decades [6-7]. The calculation and distribution of incident solar energy in closed spaces can be accomplished through a number of approaches of several levels of complexity of effect and accuracy [6]. Therefore, taking into account the sunspot (SS) in the thermal modelling of buildings has the advantage of improving the precision of the model and its performances for the calculation of the temperatures of the air and the walls as well as the accurate estimation of heating and cooling requirements. Most existing building thermal models do not take into account the impact of the evolution of SS in a room with glazing which is a rough approximation [8]. Other models take into account the modelling of short-wavelength radiation (SWL) exchanges inside the building assuming that all radiation is projected onto the floor uniformly throughout the year [7]. This hypothesis is very debatable because during the winter, the sun is quite low and can touch all the vertical surfaces [8].

Another hypothesis, yet not precise and commonly used, assumes that $60 \%$ of the SWL radiation is distributed on the floor and the rest is distributed, in proportion, to the other surfaces [9]. In other software, the percentage of flux reaching each wall is kept constant throughout the simulation period [9]. Authors in [9-11] simulated the thermal behaviour of a room with a large glass surface using four different software programs (DEROB-LTH, SUNREP (TRNSYS), FRES and TSBI3). They concluded that heating requirements in heavily glazed areas were underestimated in most software due to poor consideration of sunspot. There are other more efficient methods that calculate the SSA on each wall and at each time step. Authors in $[8,12]$ calculated and localized the SSA using the Delaunay triangularization method [13]. Author in [9] proposed a geometric calculation approach to determine the surface and the position of the SS. Depending on the positions of the window and the sun, there are 20 cases of figures and each of them has an explicit and distinct equation. Authors in [14-20] modelled and counted the SSA for a cell oriented to the west and located in Paris. The localization is verified by the application of a membership test whose principle is to verify the inclusion or not of the projections of the centers of the meshes on a plane perpendicular to the rays of the sun in the polygon resulting from the projection of the window on the same plan. To verify the validity of the obtained numerical results, authors carried out a series of tests on different periods of the year.

In our work, the model proposed in [21] is chosen to calculate and locate the SSA on the walls and on the floor of a 
room $(3 \times 3 \times 3 \mathrm{~m})$ with a window $(1 \times 1 \mathrm{~m})$ facing south. The choice of the model is based on its simplicity and its modest calculation time. This study is carried out for the $21 \mathrm{st}$ of March, June and December at the Ksar Challala site in Algeria.

\section{DESCRIPTION AND MATHEMATICAL MODELING}

To calculate locate the SSA, we must first calculate the solar time, hour angle, inclination angle and azimuth. Consider a room with a square window. The orientation of the room is identified by the azimuth $(\underline{a b})$ relative to the southern direction (Figure 1) [21]. The components of the unit vector $\overrightarrow{S O}$ in the frame $(O, X Y Z)$ are a function of the altitude $(h)$ and the azimuth (AZ) of the sun [21]:

$$
\begin{aligned}
& A=-\cos (h) \cos (A Z) \\
& B=-\cos (h) \sin (A Z) \\
& C=-\sin (A Z)
\end{aligned}
$$

In the orthonormal system $\left(O, X^{\prime} Y^{\prime} Z^{\prime}\right)$ relative to the orientation of the test cell, these components become [21]:

$$
\begin{aligned}
& A^{\prime}=A \cos (a b)+B \sin (a b) \\
& B^{\prime}=A \sin (a b)+B \cos (a b) \\
& C^{\prime}=\mathrm{C}
\end{aligned}
$$

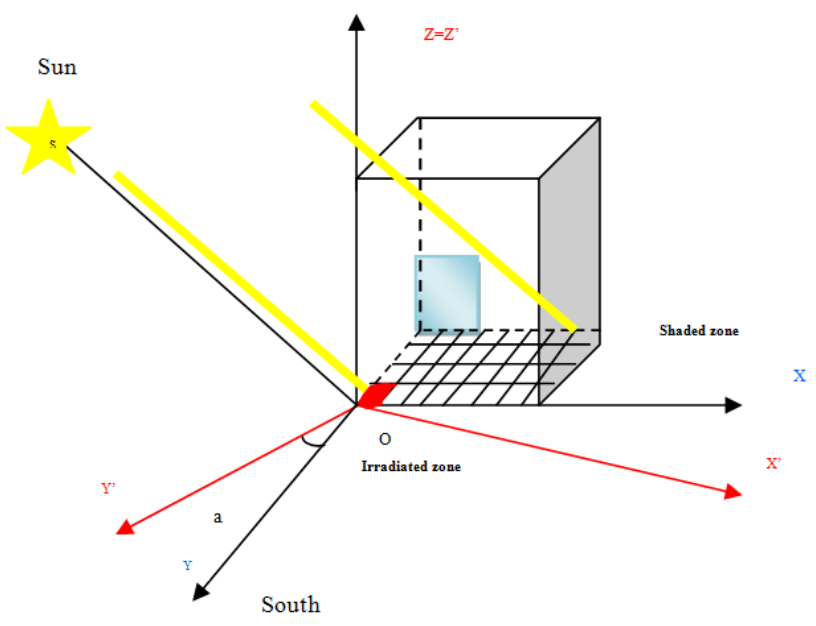

Fig. 1. The principleof the method.

To find the irradiated parts of each face of the cell, each wall is subdivided into a set of small facets (Figure 1). From the barycenter of each facet, a vector is projected whose direction is opposite to the sun. If this vector intercepts the surface of the window, the elementary surface is irradiated otherwise it is in the shadow [21]. If $\mathrm{G}(X G, Y G, Z G)$ the barycenter of the square $\mathrm{M}$ in the landmark $\left(O, X^{\prime} Y^{\prime} Z^{\prime}\right)$, the projection of $\mathrm{G}$ will be $\mathrm{G}^{\prime}\left(X G^{\prime}, Y G^{\prime}, Z G^{\prime}\right)$. As the sun is supposed in the infinity, we can write [21]:

$$
\overrightarrow{G G^{\prime}}\left(\begin{array}{c}
X G^{\prime}-X G \\
Y G^{\prime}-Y G \\
Z G^{\prime}-Z G
\end{array}\right) \wedge \overrightarrow{S O}=0
$$

where:

$$
\begin{aligned}
& X G^{\prime}=X G+\frac{A^{\prime}}{C^{\prime}}\left(Z G^{\prime}-Z G\right) \\
& \mathrm{YG}^{\prime}=\mathrm{XG}+\frac{\mathrm{B}^{\prime}}{\mathrm{A}^{\prime}}\left(\mathrm{XG}^{\prime}-\mathrm{XG}\right)
\end{aligned}
$$

$$
\mathrm{ZG}^{\prime}=\mathrm{XG}+\frac{\mathrm{C}^{\prime}}{\mathrm{B}^{\prime}}\left(\mathrm{YG}^{\prime}-\mathrm{YG}\right)
$$

By comparing these coordinates with the window's dimensions we can judge if the square $M$ is irradiated. The SSA of each wall is calculated by the sum of the irradiated elementary surfaces [21].

\section{RESULTS AND DISCUSSION}

The simulation of the SSA was done using the predescribed model by establishing a calculation code in Fortran 90 language. The obtained results are given every one minute.

\section{A. Temporal Evolution of the SSA}

The temporal evolution of the SSA on the walls affected by solar radiation according to the window's area variation between $1 \mathrm{~m}^{2}$ and $2 \mathrm{~m}^{2}$ for the $21 \mathrm{st}$ of March, June and December is examined. The analysis of the curves regarding the 21st of March (Figure 2) shows that the western wall is affected by the sun during the morning, the east wall in the afternoon and the floor in the middle of the day. The north wall is not affected during the studied days. It also appears that the SSA records its greatest values when the window area is $2 \mathrm{~m}^{2}$, meaning that the SS grows with the enlargement of the dimensions of the window. Indeed, the maximum SSA on the floor is $2.89 \mathrm{~m}^{2}$ and $0.73 \mathrm{~m}^{2}$ for a window area (Sw) of $2 \mathrm{~m}^{2}$ (Figure 2(b)) and $1 \mathrm{~m}^{2}$ (Figure 2(a)) respectively. Furthermore, it is clear that the SSA on the floor is significantly higher than those calculated for the other walls even if the dimensions of the window are increased.

(a)

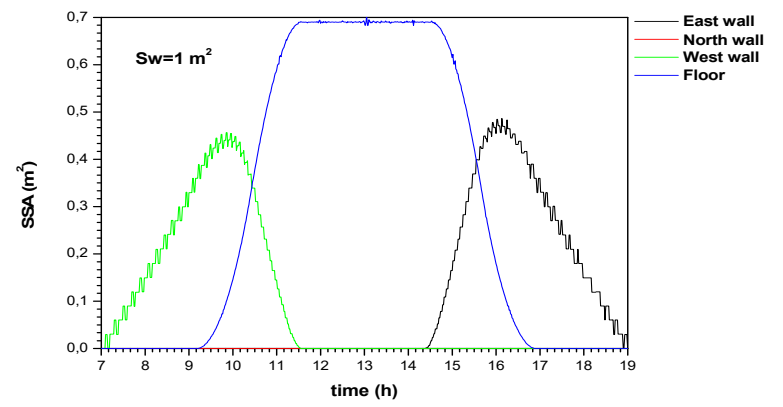

(b)

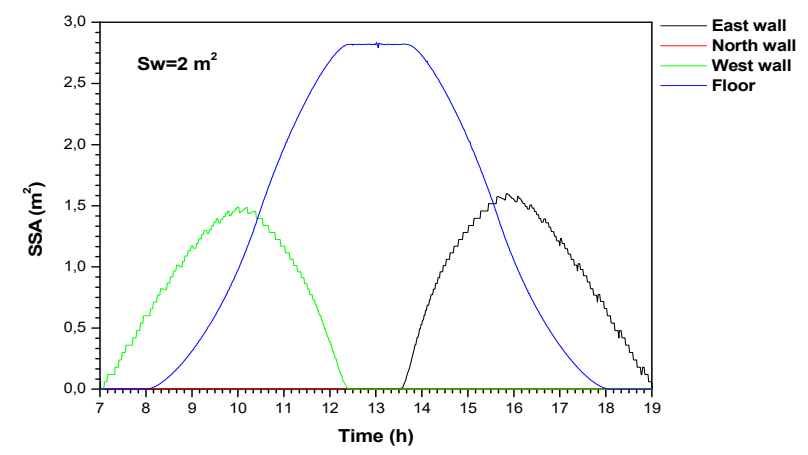

Fig. 2. Temporal evolution of the SSA according to the window area (21 March) with window area (a) $1 \mathrm{~m}^{2}$ and (b) $2 \mathrm{~m}^{2}$ 
For the summer solstice, the SSA is smaller than that obtained on the 21st of March resulting from the height of the sun which is maximum during the summer. The SS is visible on the walls only between 9:30 and 16:20. Nevertheless, it grows significantly with the increase of the glazed surface as it is clear in Figures 3(a) and 3(b). On the other hand, we can observe that the north wall is not affected by the radiation through the window. For the chosen orientation and the site study, it appears that the SS on the east wall is slightly larger than that on the west wall. The SS on the floor is clearly superior to those obtained on the vertical walls even if the glazed surface is increased.

(a)

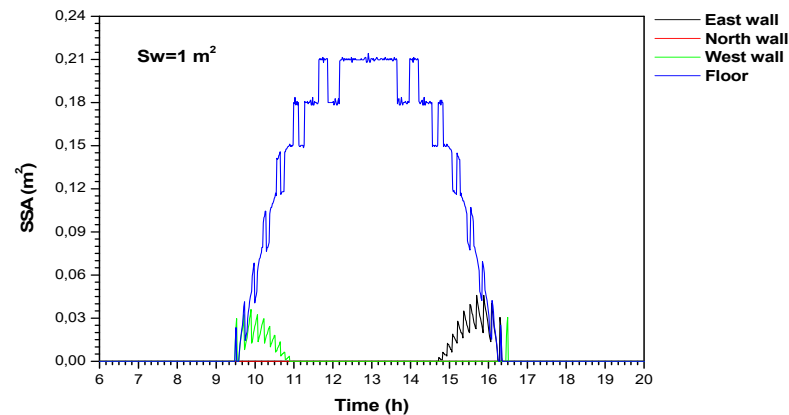

(b)

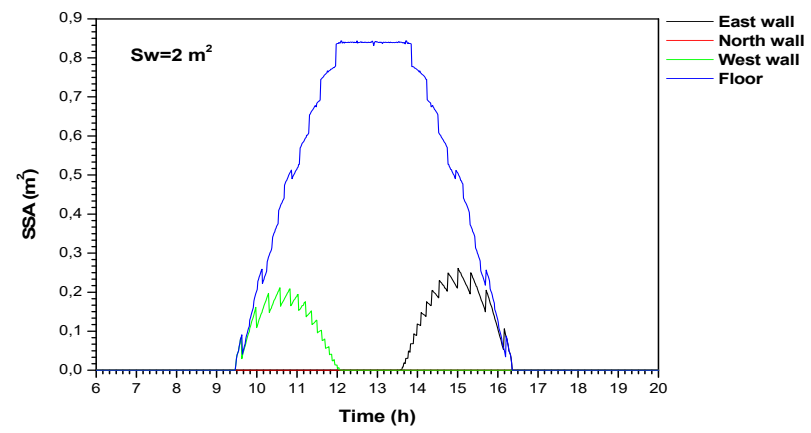

Fig. 3. Temporal evolution of the SSA according to the window area (21 June) with window area (a) $1 \mathrm{~m}^{2}$ and (b) $2 \mathrm{~m}^{2}$

For the 21st of December (Figure 4), SSA is greater than those obtained for the 21st of March and the 21st of June. It is also noted that the maximum values of the SSA on the east wall, west wall and on the floor are close opposed to the SS on the north wall which has considerably lower maximum values. It can be seen in Figures 4(a) and 4(b) that the north wall is affected by solar radiation with maximum surfaces of SS of $0.306 \mathrm{~m}^{2}$ and $1.5075 \mathrm{~m}^{2}$ for a Sw of $1 \mathrm{~m}^{2}$ and $2 \mathrm{~m}^{2}$ respectively.

\section{B. Localisation of the SSA}

We have located in Figures 5, 6 and 7 the SS on each wall and on the floor for the 21 of March, June and December respectively. In Figure 5, it is noted that at 10:00, the SS is located on the west wall and forms a trapezoidal whose base is located on the axis (OY) between $-69 \mathrm{~cm}$ and $-141 \mathrm{~cm}$. The heights of the left and right sides of the trapezoidal are respectively $104 \mathrm{~cm}$ and $9.8 \mathrm{~cm}$ (see Figure 5(a)). (a)

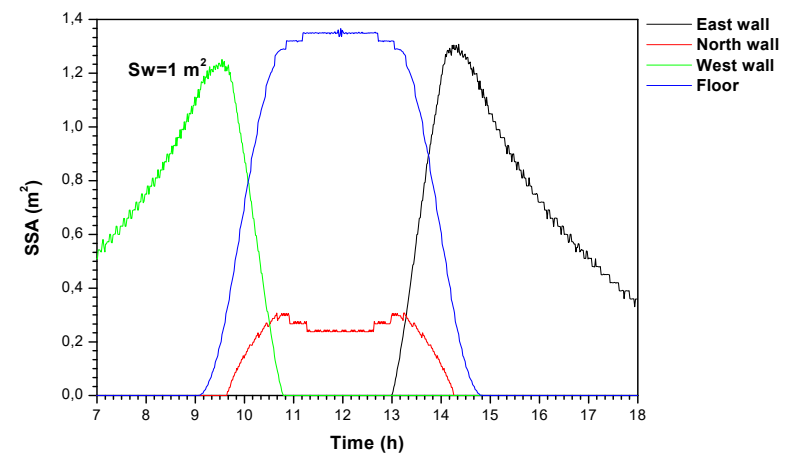

(b)

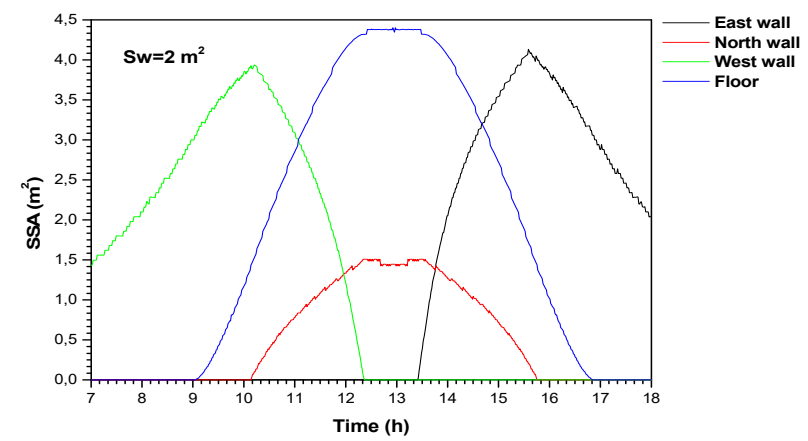

Fig. 4. Temporal evolution of the SSA according to the window's area (21 December) with window area (a) $1 \mathrm{~m}^{2}$ and (b) $2 \mathrm{~m}^{2}$

At 12:00 (Figure 5(c)), the SS is located on the floor and forms a parallelogram whose base parallel to the axis (OX) varies between $77 \mathrm{~cm}$ and $177 \mathrm{~cm}$. Its two sides are parallel and equal and vary according to the axis (OY) between $-72 \mathrm{~cm}$ and $-146 \mathrm{~cm}$. On the east wall at 15:00, the SS forms a triangular surface whose right angle is on the left, its base is on the axis (OY) and varies between $74.6 \mathrm{~cm}$ and $143.6 \mathrm{~cm}$. The height of the triangle reaches $97 \mathrm{~cm}$ (Figure 5(b)). For the summer solstice, the SS on the west and east walls occupy small surfaces as illustrated in Figures 6(a) and 6(b) respectively. Indeed, the SS is placed in the morning at 10:00 on the west wall forming a surface of $0.0261 \mathrm{~m}^{2}$ on the extreme left side of this wall (Figure 6(a)). At 15:00, we see in Figure 6(b) that the SS is located on the bottom of the left side of the wall where it occupies an area of $0.0099 \mathrm{~m}^{2}$. As for the SS on the floor, it appears clearly in Figure 6(c) that it forms a parallelogram surface whose base varies between $75 \mathrm{~cm}$ and $174 \mathrm{~cm}$, while the two sides vary between $-19 \mathrm{~cm}$ and $-40 \mathrm{~cm}$. The relatively small SSA is due to the higher solar altitude values during the summer.

For the 21st of December, at 10:00, it is noted in Figures 7(a) and 7(b) that the SS is located on the west wall and on the floor simultaneously forming a parallelogram whose lower right side is located on the floor thus forming a triangular surface. Examining Figures 7(c) and 7(d), we notice that at 12:00 the SS is located on the floor and the north wall at the same time. On the floor, the SS forms a parallelogram while on the north wall it forms a rectangular surface. At 15:00, the SS is 
located simultaneously on the floor and the east wall forming a parallelogram whose bottom left side is on the floor (Figures 7(e) and 7(f)).

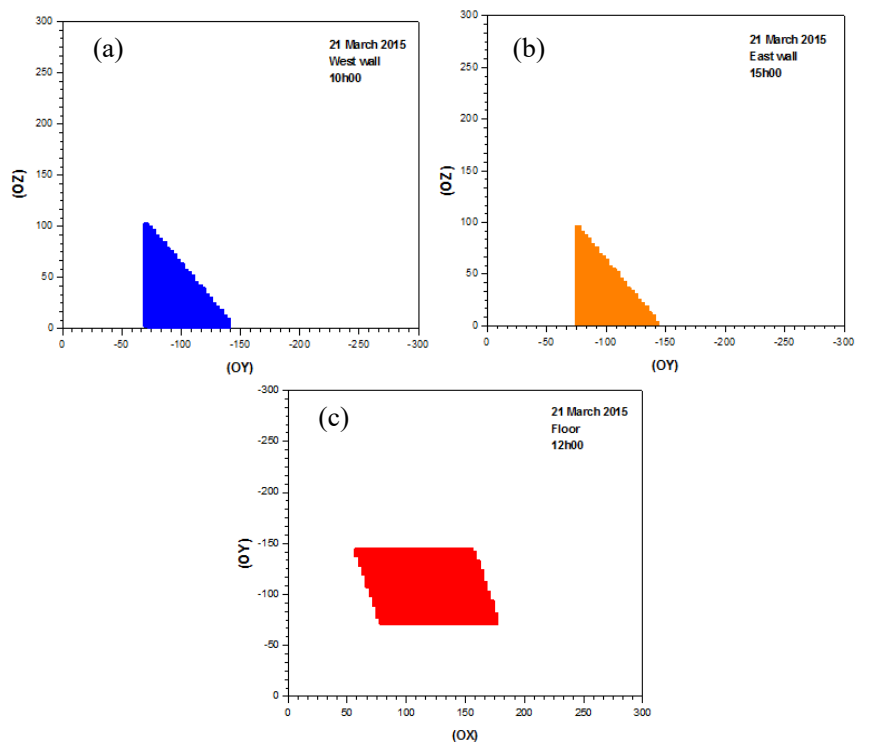

Fig. 5. SS location on the walls and on the floor for glazed surface of $1 \mathrm{~m}^{2}$
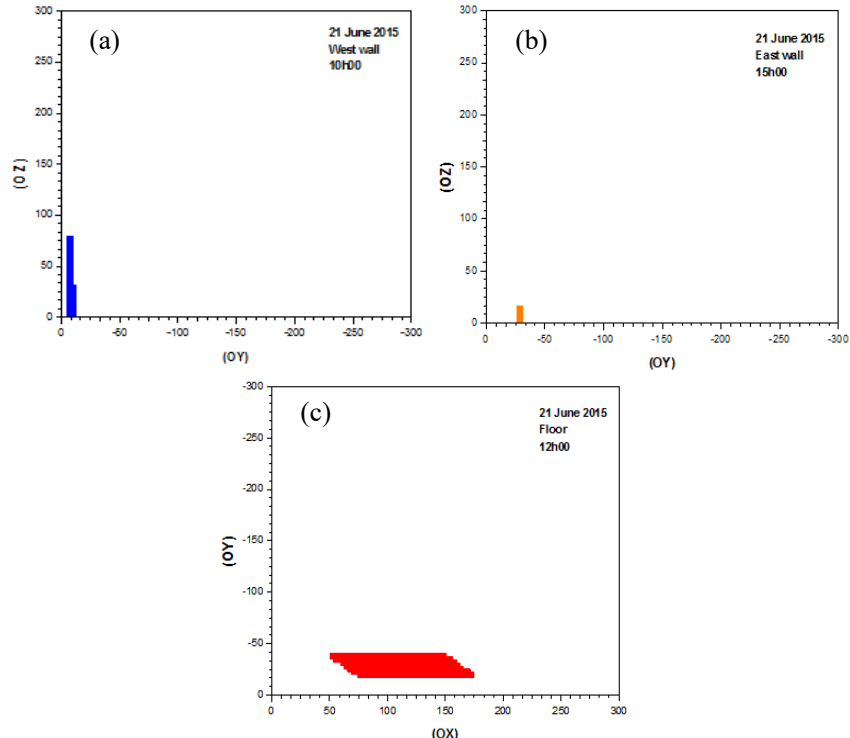

Fig. 6. SS location on the walls and on the floor for glazed surface of $1 \mathrm{~m}^{2}$

\section{SS Residence Time on the Walls and on the Floor}

The effect of the variation of the dimensions of the window on the residence time of the SS on each wall and on the floor is demonstrated in the histograms represented in Figure 8. For March 21 (Figure 8(a)), we note that the SS residence time on the floor and the walls increases with increasing window size. For the floor, the residence time increases further, it grows from $7.64 \mathrm{~h}$ to $10.03 \mathrm{~h}$ for glazed surfaces from $1 \mathrm{~m}^{2}$ to $2 \mathrm{~m}^{2}$ respectively. On June 21st, the residence time of the SS on the floor remains unchanged, while those of the SS on the east and west walls increase with increasing dimensions of the window (Figure 8(b)). As for the 21st of December, it is clear that the residence time of the SS on all the walls increases. In particular the residence time on the floor which increases by about 2 hours when the glazing surface increases from $1 \mathrm{~m}^{2}$ to $2 \mathrm{~m}^{2}$ (Figure 8(c)).
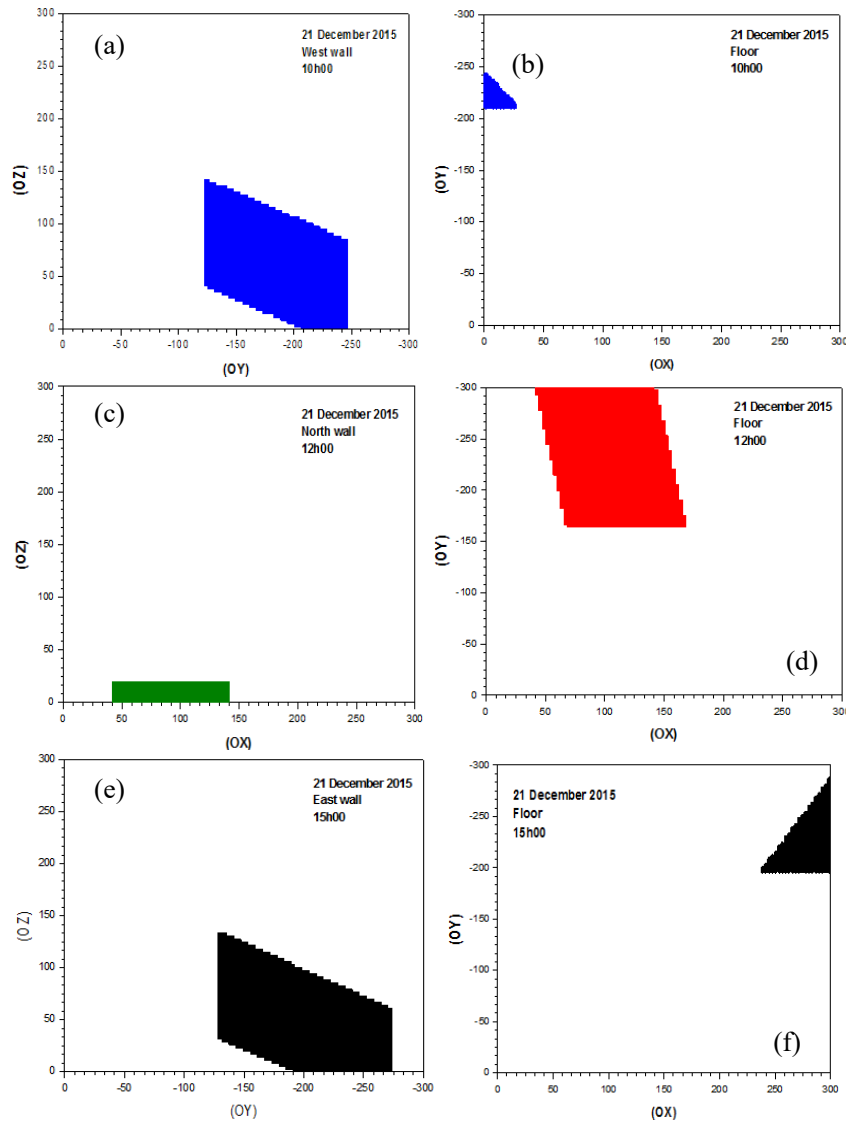

Fig. 7. Location of the SS on the walls and on the floor for a glazed surface of $1 \mathrm{~m}^{2}$

\section{CONCLUSION}

Current research concerns the accounting and localization of the SSA on the walls and on the floor of a room $(3 \times 3 \times 3 \mathrm{~m})$ equipped with a window $(1 \times 1 \mathrm{~m})$ on its southern wall, located in the site of Ksar Challala. In order to demonstrate the effect of the variation of the glass surface on the SSA, we varied the window area between $11.1 \%$ and $33.3 \%$ of the surface of the south wall for the 21st of March, June and December. The analysis of the results obtained leads to the following conclusions:

- The western wall is affected by the sun in the morning, the eastern wall in the afternoon, the floor and the north wall in the middle of the day.

- The north wall is affected by solar radiation only on the 21 st of December because of the relative low values of the solar height.

- By increasing the window's area from $1 \mathrm{~m}^{2}$ to $2 \mathrm{~m}^{2}$, we found that the SSA increases considerably. 
- The residence time of the SS on the walls and on the floor rises with the increase of the SSA except the residence time of the SS on the floor for the 21st of June which remains unchanged.

(a)

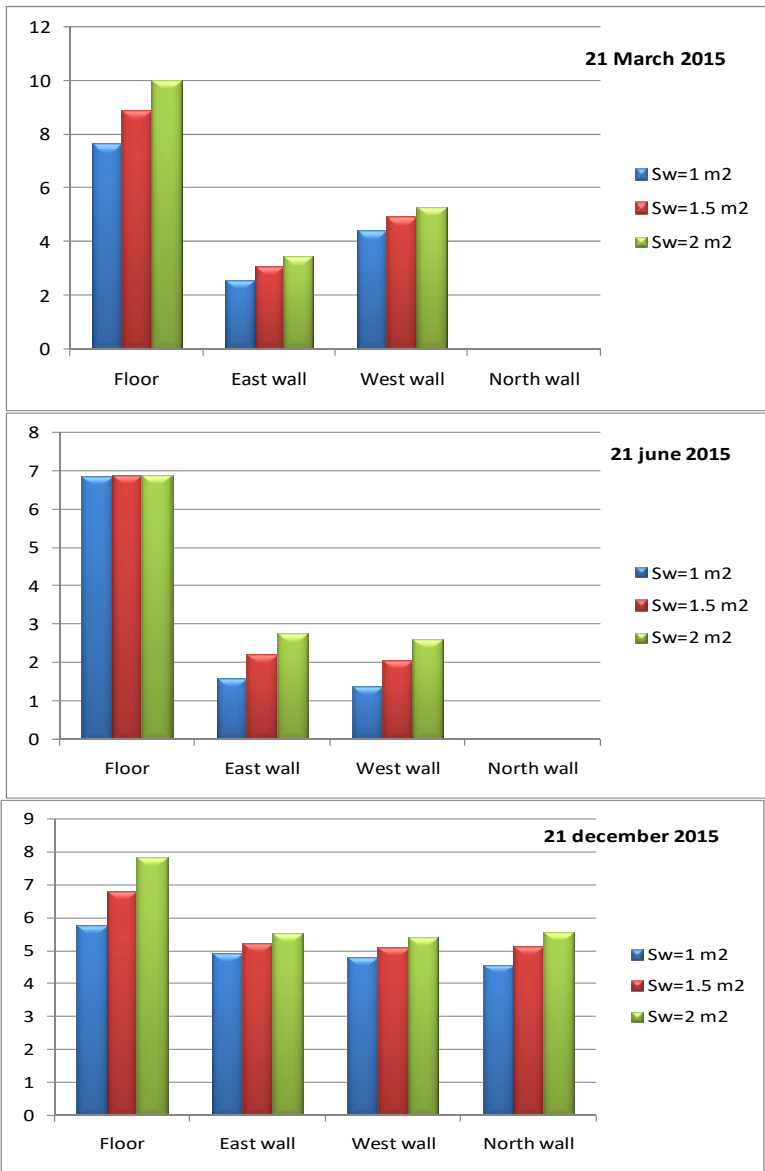

Fig. 8. Variation of the residence time of the SS on the walls and on the floor according to the dimensions of the window

\section{REFERENCES}

[1] C. Tian, T. Chen, H. Yang, T. Chung, "A generalized window energy rating system for typical office buildings", Solar Energy, Vol. 84, No. 7, pp. 1232-1243, 2010

[2] F. Gloriant, P. Tittelein, A. Joulin, S. Lassue, "Comparaison de deux modèles numériques d'une fenêtre pariéto-dynamique de type PAZIAUD ${ }^{\circledR}$ en vue d'une simulation en thermique du bâtiment", XXXe Rencontres AUGC-IBPSA Chambéry, Savoie, June 6-8, 2012 (in French)

[3] F. Gloriant, P. Tittelein, A. Joulin, S. Lassue, "Modeling a triple-glazed supply-air window", Building and Environment, Vol. 84, pp. 1-9, 2015

[4] T. Catalina, J. Virgone, J. Roux, E. Blanco, "Effet de l'inertie thermique, de la surface vitrée et du coefficient de forme sur les besoins en chauffage d'une habitation", Congrés IBPSA, Lyon, France, November, 2008 (in French)

[5] M. Persson, A. Roos , M. Wall, "Influence of window size on the energy balance of low energy houses", Energy and Buildings, Vol. 38, No. 3, pp. 181-188, 2006

[6] K. Chatziangelidis, D. Bouris, "Calculation of the distribution of incoming solar radiation in enclosures", Applied Thermal Engineering, Vol. 29, No. 5-6, pp. 1096-1105, 2009
[7] Y. G. Yohanis, B. Norton, "Useful solar heat gains in multi-zone nondomestic buildings as a function of orientation and thermal time constant", Renewable Energy, Vol. 27, No. 1, pp. 87-95, 2002

[8] H. Bouia, J. Roux, C. Teodosui, "Modélisation de la tache solaire dans une pièce équipée d'un vitrage utilisant un maillage en surface de Delaunay", France, November, 2002 (in French)

[9] P. Tittelein, Environnements de simulation adaptés à l'étude du comportement énergétique des bâtiments basse consommation, $\mathrm{PhD}$ Thesis, Université de Savoie, 2008

[10] M. Wall, "Distribution of solar radiation in glazed spaces and adjacent buildings. A comparison of simulation programs", Energy and Buildings, Vol. 26, No. 2, pp. 129-135, 1997

[11] M. H. Benzaama, M. Lachi, C. Maalouf, A. M. Mokhtari, G. Polidori, M. Makhlouf, "Study of the effect of sun patch on the transient thermal behaviour of a heating floor in Algeria", Energy and Buildings, Vol. 133, pp. 257-270, 2016

[12] H. Bouia, J-J. Roux, "Application de la triangulation de Delaunay au calcul des facteurs de forme entre deux surfaces planes quelconques", Congrès français de Thermique, SFT2002, Vittel, June 3-6, 2002 (in French)

[13] J. Jan, Rayonnement solaire: aspects géométriques et astronomiques, Collection Cours et Manuels, Ministère des Transports, Direction de la Météorologie, 1983 (in French)

[14] A. Rodler1, J. Virgone, J. J. Roux, "Impact of sun patch and threedimensional heat transfer descriptions on the accuracy of a building's thermal behavior prediction", Building Simulation, Vol. 9, No. 3, pp. 269-279, 2016

[15] A. Rodler, J. J. Roux, J. Virgone, E. J. Kim, J. L. Hubert, “Are 3D heat transfer formulations with short time sted and sun patch evolution nececessary for building simulation?", Building simulation conférence, Aix-les-Bains, France, pp. 3737-3744, 2013

[16] A. Rodler, J. Virgone, J. J. Roux, J. L. Hubert, "Development and validation of a three dimensional thermal transientnumerical model with sun patch: Application to a low energy cell", Energy and Buildings, Vol. 87 , pp. $425-435,2014$

[17] A. Rodler, J. Virgone, J. J. Roux, E. J. Kim, J. L. Hubert, "Impact de la tache solaire sur un modéle thermique tri-dimensionnel de bâtiment : application à une cellule fortement isolée", XIème Colloque Interuniversitaire Franco-Québécois sur la Thermique des Systèmes, Reims, France, June 3-5, 2013 (in French)

[18] A. Rodler, J. Virgone1, J. J.Roux1, H. Castet, R. Le Berre, M. Baranzini, J. L. Hubert, "Expérimentation in situ sur la cellule BestLab pour la validation d'un modèle prenant en compte la tache solaire", Conférence IBPSA France-Arras, 2014 (in French)

[19] A. Rodler, J. Virgone, J. J. Roux, "Impact of the sun patch on heating and cooling power evaluation for a low energy cell", CISBAT 2013, Lausanne, Switzerland, 2013

[20] A. Rodler, J. Virgone, J. J. Roux, "Sun Patch Impact for the Evaluation of Operative Temperatures Distributions", Study of Civil Engineering and Architecture, Vol. 3, pp. 130-134, 2014

[21] Y. Boukhris, L. Gharbi, N. Ghrab-Morcos, "Coupling the building simulation tool ZAER with a sunspot model. Case study in Tunis", Energy and Buildings, Vol. 70, pp. 1-14, 2014 